\title{
Standards and Protection
}

\author{
Ronald Fischer \\ Pablo Serra
}

\section{SERIE ECONOMIA $\mathbf{N}^{\circ} \mathbf{4 5}$ \\ Noviembre, 1998}

Centro de Economía Aplicada

Departamento de Ingeniería Industrial

Facultad de Ciencias Físicas y Matemáticas

Universidad de Chile 


\title{
Standards and Protection
}

\author{
Ronald Fischer* Pablo Serra
}

\begin{abstract}
This paper examines the behavior of a country that imposes a minimum standard on a good produced both by a domestic firm and by a foreign competitor, and where the latter also supplies its own market. Production costs rise with the standard, and the foreign firm incurs a fixed setup cost if it produces at two standard levels. When the domestic government raises the minimum standard, the foreign producer has to choose between sacrificing exports, facing higher production costs on its entire output, or incurring the fixed setup cost. Depending on the size of the foreign market and the fixed setup cost, the domestic firm will lobby for the lowest minimum standard that excludes the foreign firm or for no standard at all. When consumption of the good produces an externality, the domestic social planner sets a minimum standard which is a non-increasing function of the size of the foreign market. When an externality is present, we show that the planner is always protectionist in the sense that it chooses a higher standard than the one it would set if both firms were domestic.
\end{abstract}

Keywords: Minimum standards; Protectionism; Consumption externality.

JEL classification: F12, F13.

\footnotetext{
*Centro de Economía Aplicada, Departamento de Ingeniería Industrial, University of Chile. We are thankful for comments by Alex Galetovic and two unknown referees. Ronald Fischer gratefully acknowledges support from FONDECYT, Project 1950513 and a grant from the Mellon Foundation. Pablo Serra is grateful for the support of the Mellon Foundation. Please direct correspondence to: rfischer@dii.uchile.cl. This paper builds on previous work that appeared in Fischer and Serra (1997).
} 


\section{Introduction}

As multilateral agreements lower tariff barriers, more subtle forms of protection are becoming common. One of the mechanisms that have recently acquired relevance is the use of minimum standards which are biased against imports. ${ }^{1}$ As norms and standards usually apply to both national and foreign production, they do not correspond to the classical forms of protectionism, which openly discriminate against imports. However, minimum standard may cloak protectionist intentions. Moreover, it is even possible that protection is the only goal of the standard. An example of this type of standards are marketing orders, which, as Bockstael (1984) points out, are usually applied to features which are visible to consumers. An illustrative case is the USA's imposition of a larger minimum size requirement on vine-ripened tomatoes, normally imported from Mexico, than on green tomatoes, mainly produced in Florida (Bredahl et al. (1987)).

The Chilean regulations concerning beef represent a prime example of standards which are designed to prevent imports. In the late 1970's, Chile established a policy of eradication of mouth and hoof disease (a disease afflicting cattle). Among other things, it banned meat imports from countries which have the disease, with the argument that this would enable Chilean beef producers to export to developed countries. This policy, pursued for almost 15 years, resulted in almost no exports, as Chile has no comparative advantage in meat production. It was successful in limiting imports from Argentina, a country with a huge comparative advantage in meat production which had endemic mouth and hoof disease. Implementing the policy was expensive, since it is easy to smuggle cattle from Argentina, as both countries share a two and a half thousand mile border. Smuggling led to periodic and localized outbursts of the disease and the ensuing slaughter of affected cattle.

By the early 90's, however, Argentinean exporters had developed vacuum packaging of de-boned meat, and beef exports to Chile grew fast. Moreover, Argentina began its own eradication policy for hoof and mouth disease. In response, Chile introduced a system for grading meat quality which is incompatible with the systems of Argentina and the US, another big meat exporter. Beef producers in those countries argue that the cost of setting a special grading system in order to export to such a small market, raises prices and hence protects local producers.

The 1947 GATT accords allowed the use of minimum standards to protect human, animal and plant health, as well to bring order to a market. Although the accords expressly stated that standards should not be used as covert forms of protectionism, GATT jurisprudence shows that it is not easy to prove that a minimum standard has a protectionist aim. The recent Marrakesh accords setting up the World Trade Organization (WTO) established that standards can differ from internationally accepted levels only when there is scientific evidence supporting the decision. Despite this agreement, the US National Research Council (NRC) (1995) predicts that the use of

\footnotetext{
${ }^{1}$ We use the notion of a minimum standard rather than the more common minimum quality standard, because the standards we analyze have no direct effect on the utility of consumers
} 
standards as a tool of protection will become more and more important. As the NRC points out, there are few studies that have attempted to analyze the use of standards as a protectionist barrier. This paper aims to partly fill this gap.

We consider the case of a homogeneous good produced by two firms: a domestic and a foreign firm. The latter exports and also produces for its own national market. ${ }^{2}$ We assume that the standard is reflected in a change in the level of a negative consumption externality, as in Copeland and Taylor (1995). One example of this type of minimum standard is the requirement that automobiles have a catalytic converter. Other examples of standards that reduce consumption externalities are the requirements that aerosols and refrigeration equipment do not contain CFCs in order to protect the ozone layer, standards on biodegradable detergents and rules relating to the recycling of bottles and packaging materials. Although we motivate our analysis by resorting to several examples of environmental and emission standards, we prefer to use the general concept of standards, as our results also apply to phyto-sanitary restrictions on imports of agricultural products and the licensing requirements on certain professions that impede the free flow of human capital.

We assume that in order to produce under two standards the foreign firm must incur a fixed setup cost. Hence an increase in the minimum standard demanded by the domestic country, over and above the worldwide standard, compels the foreign firm to choose between raising its standard (and, therefore, the costs of its entire production), incurring the setup cost for producing under two standards, or simply abandoning exports and concentrating on its own local market. In our analysis, we first derive the behavior of the foreign firm as a function of the minimum standard set by the home country. Next, we derive the conditions under which the domestic firm will want to impose a minimum standard that excludes its foreign rival. We show that there is a threshold such that if the lowest minimum standard that excludes the foreign firm exceeds it, the local firm prefers a duopoly with no standard. Otherwise, it prefers the lowest minimum standard that excludes the foreign firm. The intuition is direct: Raising standards also increases costs for the domestic firm. ${ }^{3}$

We turn next to the analysis of the behavior of the local social planner (LSP), by examining first the case where there is no consumption externality, so the only reason to impose a standard is to exclude the foreign firm. In this case the decision-making process of LSP is analogous to that of the local firm. We show, however, that the non-exclusion threshold preferred by LSP is higher (i.e. less exclusive) than the one preferred by the the domestic firm. The intuition is that the LSP includes consumers' welfare in its objective function, which is reduced when the domestic firm's

\footnotetext{
${ }^{2}$ We have implicitly assumed that the domestic firm does not export to the foreign market. This can be explained in terms of the domestic firm having higher costs, and only being able to compete in its own market due to the transport costs faced by the foreign firm. Even where the two firms have identical production costs, differences in transport costs might explain the direction of trade of this paper. The difference in transport costs may be due to a trade imbalance. For example, refrigerated ships travelling from Europe to Chile charge lower rates than when they carry fresh fruit from Chile to the European markets.

${ }^{3}$ The dichotomous nature of the decisions follows from our assumption of a fixed setup cost of production under two standards.
} 
market power increases due to exclusion of the foreign firm. We then proceed to consider the case of consumption externalities such as pollution. We show that in this case the LSP always chooses a positive minimum standard which is a non-decreasing function of the lowest minimum standard that excludes the foreign firm.

Next we show that, for a given value of the setup cost for producing a second standard, the lowest minimum standard that excludes the foreign firm is a non-increasing function (strictly decreasing in a range) of the relative size of its own market. The foreign firm decides not to export when the cost of producing two standards is too high and exports represent a small fraction of the foreign firm's sales. It would be too expensive to either produce under two standards or rise the quality for the whole production relative to the benefits of supplying the home market. It follows that minimum standard chosen by the LSP is non-increasing in the relative size of the foreign market. We also show that the minimum standard chosen by the planner is greater than the one desired by the domestic firm in two cases: when the relative size of the foreign market is either small or large. There is an intermediate range in which the LSP and the domestic firm choose the same standard. Finally, it is possible for there to be a range of relative sizes where the domestic firm prefers a higher minimum standard than the planner, with the object of excluding the foreign firm.

When there is a negative consumption externality, it is legitimate to impose a minimum standard to correct it, even when this affects foreign producers. We assume the most favorable case for standards, i.e., when the effects of the standard are not perceived by consumers but a higher standard abates a negative externality. However, the minimum standard set by the LSP may be stricter than needed to counteract the externality, thereby incorporating a protectionist element. There are two motives for this: firstly, rents can be transferred from the foreign to the local producer; and, secondly, part of the costs of reducing the externality are absorbed by the foreign producer. This motivates the definition of a protectionist standard as one that is higher than the standard the planner would choose if all firms were domestic. Using this definition we show that the minimum standard preferred by the planner is always higher when one of the firms is foreign than when all production is domestic. Hence we conclude that the planner is protectionist.

A series or articles have studied product quality standards as a trade barrier (for example Bredahl et al (1987), Bockstael (1984), Chambers and Weiss (1992)). However, the present study would appear to be the first to stress the strategic use of minimum standard for consumption externalities. In general the literature analyzing the use of standards for strategic purposes has concentrated on environmental production standards (Barret (1994) and Kennedy (1994)). ${ }^{4}$ These authors use rent-transfer arguments similar to those of Brander and Spencer (1985) to show that countries have an incentive to lower their environmental standards so as to reduce production costs and become more competitive in foreign markets. As in Brander and Spencer (1985), the simultaneous use of standards as a strategic trade instrument has negative consequences for the

\footnotetext{
${ }^{4}$ Copeland and Taylor (1995) analyze consumption externalities in a general equilibrium setting.
} 
two countries. However, unlike the articles cited, in our case the country's social planner raises standards. The explanation is due to the fact that in those papers, firms compete in a third market, while in this article the firms compete in the home country.

Das and Donnenfeld (1987) examine the effect of tariffs, quotas and minimum standards for the quality of imports when a good is imported from a monopoly supplier or when it is produced competitively. Das and Donnenfeld (1989) examine the case of a duopoly comprising a foreign and a domestic firm. These authors study the effects on quality of tariffs, quotas and MQS and obtain the surprising result that an MQS raises quality but reduces the profits of the domestic firm, while the foreign firms sees its profits go up. However, these papers do not examine the role of externalities as a motive for imposing an MQS.

In a recent paper, Boom (1995) develops a duopoly model with vertical product differentiation, where each firm is localized in one country. Each firm can produce a single quality, for which reason the quality standard imposed by any one country alters the decisions of both firms. In that paper, as in all the literature on vertical differentiation, it is assumed that quality increases the utility of consumption. The author shows that if a country raises its minimum quality standards (MQS), consumers benefit by an increase in quality and a reduction in prices, provided both firms continue supplying both markets. Boom suggests that the MQS can be used as a technical barrier to trade, but she does not develop this possibility further.

The rest of this paper develops the ideas contained in this introduction. The next section describes the model and analyzes the preferences of the local firm over standards, section 3 derives the social welfare maximizing standard and provides a definition of a protectionist standard, the fourth section relates standards to relative market size. In section 5 , the minimum standard that maximizes social welfare is related to relative market size. The final section presents the conclusions of this study.

\section{The Model}

We consider a two country world. There is a homogeneous good produced by two firms, one national and one foreign. The foreign firm produces for its own local market and for export. The domestic firm does not export to the foreign country, due to high transport costs or for other reasons. ${ }^{5}$ Firms compete in quantities; they have identical constant marginal costs, which depend on the standard. We further assume that standard has no effect on demand for the good, as probably occurs for many environmental standards.

The domestic country does not impose explicit trade restrictions, which in principle implies that the ex-ante behavior of the two firms corresponds to that of a symmetric duopoly. More formally the domestic firm solves:

\footnotetext{
${ }^{5}$ For an explanation of this point, see footnote 2 .
} 


$$
\max _{\left\{q_{h}\right\}} \Pi\left(q_{h} ; q_{f} ; \tau\right)=p\left(q_{h}+q_{f}\right) q_{h}-c(\tau) q_{h}
$$

where $\Pi$ is the domestic firm's profits, $q_{h}$ and $q_{f}$ are the domestic firm's sales and foreign firm exports respectively, and $p$ is the domestic inverse demand function, which is assumed to have a negative slope. The parameter $\tau \in \mathbb{R}^{+}$represents the minimum standard set in the home market $(\mathrm{H})$. We use $c(\tau)$ to denote (constant) unit production costs at standard level $\tau$. Unit production costs rise with the standard (i.e. it is more expensive to produce at a higher standard) and are convex in the standard (i.e. raising the standard becomes increasingly costly). These conditions can be expressed as:

$$
c^{\prime} \geq 0, \quad c^{\prime \prime}>0, p^{\prime}<0
$$

Given that unit costs are an increasing function of the standard, and that the standard does not alter the demand for the good (because the only effect of the standard is a reduction in the externality), firms will always produce at the minimum permitted standard. We use an asterisk to distinguish variables corresponding to the foreign country. We assume that the foreign country has an optimal minimum standard which is fixed and is lower than the standard in the domestic country. Without loss of generality, the foreign standard is set at zero. In section 3.3 we show that the foreign standard is always lower than the domestic standard, so the assumption implies no restriction.

If the foreign firm does not export it solves:

$$
\Pi_{0}^{*}(\tau)=\max _{\left\{q^{*}\right\}}\left\{p^{*}\left(q^{*}\right) q^{*}-c(0) q^{*}\right\}
$$

where $\Pi_{0}^{*}$ represents profits, $p^{*}$ the inverse demand function in the foreign-country market and $q^{*}$ are its sales in that market. ${ }^{6}$ On the other hand, if the foreign firm exports, it must choose one of two options: either producing under one standard or producing under two standards and incurring in the setup cost. In the first option it must solve:

$$
\Pi_{1}^{*}(\tau)=\max _{\left\{q_{f}, q^{*}\right\}}\left\{p\left(q_{h}+q_{f}\right) q_{f}+p^{*}\left(q^{*}\right) q^{*}-c(\tau)\left(q_{f}+q^{*}\right)\right\}
$$

If it incurs in the fixed cost $F$ of setting up for production under two standards, it solves: ${ }^{7}$

$$
\Pi_{2}^{*}(\tau)=\max _{\left\{q_{f}, q^{*}\right\}}\left\{p\left(q_{h}+q_{f}\right) q_{f}+p^{*}\left(q^{*}\right) q^{*}-c(\tau) q_{f}-c(0) q^{*}-F\right\}
$$

\footnotetext{
${ }^{6}$ Note that this expression does not depend on $\tau$, which we include for notational consistency.

${ }^{7} \mathrm{We}$ assume the fixed cost $\mathrm{F}$ is such that $p\left(q_{h}+q_{f}\right) q_{f}-c(0) q_{f}-F \geq 0$. This alternative does not add anything to the analysis as production under two standards is always unprofitable.
} 
Therefore, assuming constant marginal utility of income, and that there are no costs involved in verifying whether the good complies with the minimum standard, social welfare in $\mathrm{H}$ can be expressed as gross consumer surplus plus the effect of the negative consumption externality, minus the cost of local production and minus the cost of imports, i.e.,

$$
W^{d}(\tau)=\int_{0}^{q} p(s) d s+L(q, \tau)-c(\tau) q_{h}-p(q) q_{f}
$$

where $q \equiv q_{h}+q_{f}$ is total consumption in $\mathrm{H}$ and $L(q, \tau)<0$ is the loss associated with the externality. When the minimum standard keeps imports out, social welfare is equal to gross consumer surplus, plus the negative externality and minus the cost of local production:

$$
W^{m}(\tau)=\int_{0}^{q_{h}} p(s) d s+L\left(q_{h}, \tau\right)-c(\tau) q_{h}
$$

A rise in the domestic minimum standard lowers the export incentive for the foreign firm. To demonstrate this result formally, we need to impose a technical condition on the concavity of the demand functions, thereby guaranteeing the stability of the Cournot equilibrium in $\mathrm{H}$.

Condition $1 p^{\prime \prime} q_{i}+p^{\prime}<0, p^{* \prime \prime} q^{*}+p^{* \prime}<0 i=h, f$.

\section{Proposition 1 If condition 1 is fulfilled}

1. The foreign firm's profits from exports fall as the minimum standard is raised in $H$.

2. Under monopoly, the domestic firm's profits fall as the minimum standard is raised.

Proof: See appendix.

If there is no minimum standard in country $\mathrm{H}$, the foreign firm will always export. As we have assumed there is no minimum standard in the foreign country, returns from exports fall as the minimum standard is raised in country $\mathrm{H}$, because the foreign firm has to comply with the requirement for the export market and, eventually, for its own market (in case it prefers not to incur the fixed cost of producing under two standards). When the foreign firm does not export, its profits do not depend on the minimum standard set by $\mathrm{H}$.

There is, therefore, a minimum standard $\tau_{e}$ in $\mathrm{H}$ which leaves the foreign firm indifferent between exporting and producing solely for its own market with no standard..$^{8}$ This minimum standard $\tau_{e}$ is the solution to:

$$
\Pi_{0}^{*}(\tau)=\operatorname{Max}\left\{\Pi_{1}^{*}(\tau), \Pi_{2}^{*}(\tau)\right\}
$$

\footnotetext{
${ }^{8} \mathrm{As}$ costs are convex and increasing in $\tau$, there exists a minimum standard such that the foreign firm obtains zero profits in the export market.
} 


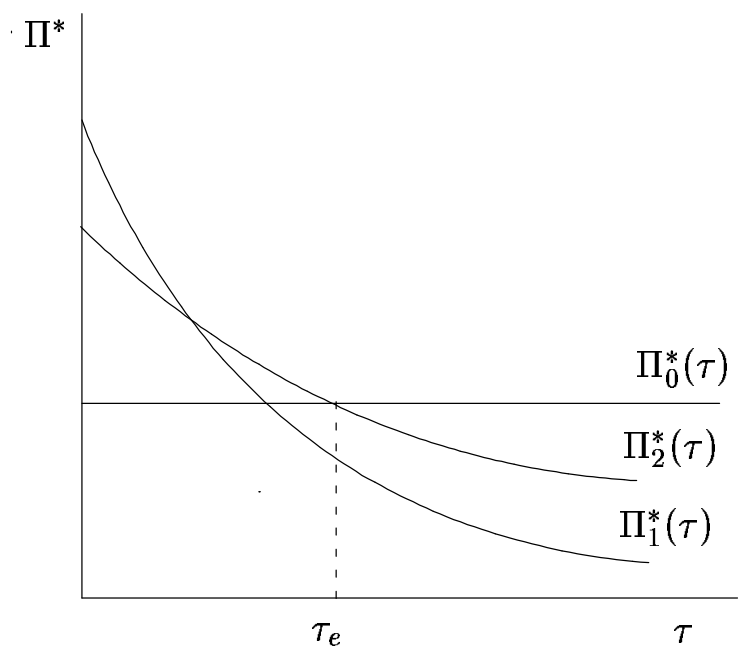

Figure 1: Profits of the foreign firm as a function of standard

Figure 1 shows the standard which leaves the foreign firm indifferent between exporting and not doing so. The slope of the curves is a consequence of proposition 1 . Note that there are two possible cases: first, that this standard corresponds to the intersection of $\Pi_{0}^{*}(\tau)$ and $\Pi_{2}^{*}(\tau)$; and second, to the intersection of $\Pi_{0}^{*}(\tau)$ and $\Pi_{1}^{*}(\tau)$. In Figure 1, the rightmost crossing, which determines $\tau_{\boldsymbol{e}}$, occurs for the case of production under two standards.

We now consider the problem facing the domestic firm which has to decide whether to press for the lowest minimum standard that drives the foreign firm away or for a duopoly with no standard. So as not to complicate the exposition, we assume that the foreign firm does not export when $\tau=\tau_{e}$. Figure 2 shows the domestic firm's profit under monopoly and duopoly as functions of the standard $\tau$ (the superscript $d$ indicates duopoly and $m$ indicates monopoly.) The curve drawn in bold represents profits earned by the domestic firm at each minimum standard. The jump in profits that occurs when standard $\tau_{e}$ is reached, is the result of a change in regime from duopoly to monopoly. This happens when the foreign firm decides not to export, due to the fact that the minimum standard in country $\mathrm{H}$ is too high.

Note that the only standards that are relevant to the domestic firm's decisions are the null standard (corresponding to point A) if the firm prefers a duopoly, and the standard $\tau_{\boldsymbol{e}}$ (corresponding to point B), when it prefers a monopoly, as can be seen in Figure 2. We define standard $\tau_{d}$, as the standard that makes the domestic firm indifferent between monopoly (at standard $\tau_{d}$ ) and duopoly with no standard. Thus, if the standard that excludes the foreign firm $\left(\tau_{e}\right)$ is greater than $\tau_{d}$, the domestic firm prefers a duopoly with no standard. Otherwise it prefers a monopoly with standard $\tau_{e}$. 


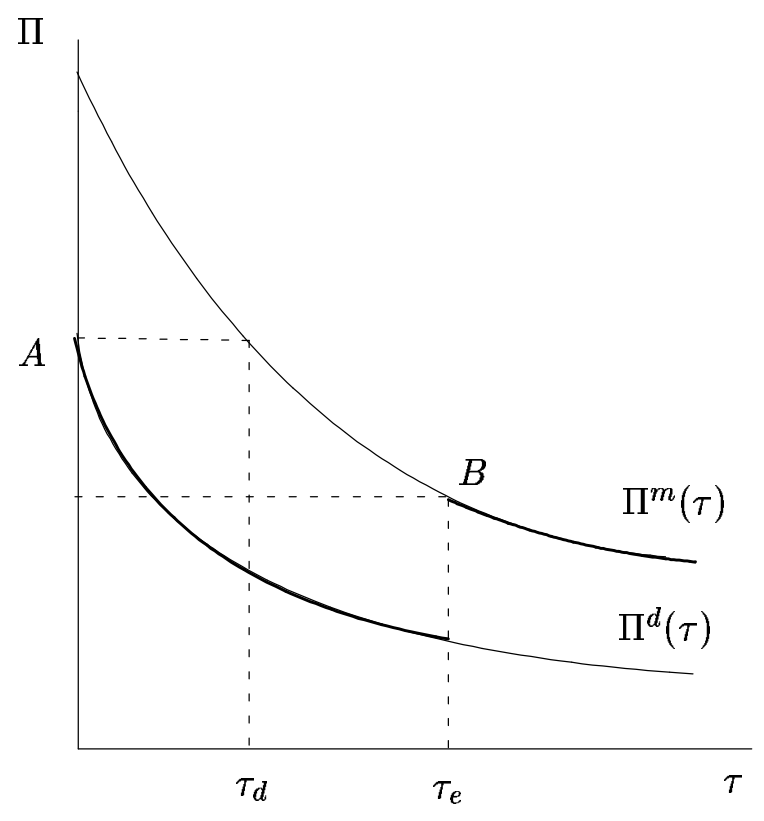

Figure 2: Profits of the domestic firm under monopoly and duopoly.

\section{The Social Welfare Maximizing Standard}

This section studies decision-taking by the local social planner. The LSP considers the welfare of society at large. Hence its objectives could include shifting rents towards the domestic producer by imposing minimum standards that drive away the foreign firm. However, this mechanism is constrained by two factors. First, a new standard raises the domestic firm's production costs; and second, it increases the market power of the local firm. We begin our analysis by considering the case where there is no consumption externality, a situation in which standards are clearly protectionist. ${ }^{9}$ Next we tackle the case where there exists a standard-dependent externality. Finally we define a consistent definition of a protectionist standard.

\subsection{The no-externality case $^{10}$}

With no externality the social welfare functions $W^{m}(\tau)$ and $W^{d}(\tau)$ are decreasing (recall proposition 1), the LSP's decision is analogous to that of the domestic firm. ${ }^{11}$ Therefore, the planner chooses between no minimum standard $(\tau=0)$ and setting the lowest standard that excludes the

\footnotetext{
${ }^{9}$ For instance, according to the National Research Council (1995), the European Union's prohibition of beef imports from animals treated with growth hormones would fall in this category because the NRC claims there are no scientific arguments supporting prohibition.

${ }^{10}$ Note that in this case the optimal minimum standard is $\tau=0$ in the foreign country.

${ }^{11}$ The plots of $W^{d}(\tau)$ and $W^{m}(\tau)$ in the case of no externalities are similar to the profit functions in Figure 2.
} 
foreign firm $\left(\tau_{e}\right)$, as a higher minimum standard would needlessly distort the economy. The LSP must weigh the fact that although under duopoly rents get exported, there is also more competition.

As social welfare includes consumers' surplus, it could occur that $W^{d}(0) \geq W^{m}(0)$. In this case, the LSP will choose to impose the null standard independently of $\tau_{e}$, hence we always have a duopoly in this case. If $W^{m}(0) \geq W^{d}(0)$, there is a value $\tau_{s}$, such that $W^{m}\left(\tau_{s}\right)=W^{d}(0)$. Then if the lowest standard that excludes the foreign firm $\left(\tau_{e}\right)$ is lower than $\tau_{s}$, the LSP chooses a monopoly with standard $\tau_{e}$. Otherwise it chooses a duopoly with no standard.

As the LSP considers societal welfare and not only the welfare of producers, intuition suggests that the social planner is more likely to prefer a duopoly with no standards than the domestic firm. To show this, let $q(\tau)$ denote production levels when the minimum standard is $\tau$. Net consumer surplus is the difference between social welfare and domestic firm profits:

$$
W(\tau)-\Pi(\tau)=\int_{0}^{q(\tau)} p(s) d s \quad-p(q(\tau)) q(\tau)
$$

Now, monopoly consumption is always smaller than duopoly consumption, and in addition production cost under the minimum standard required to have a monopoly in $\mathrm{H}$ are higher, so $\left(W^{m}\left(\tau_{d}\right)-\Pi^{m}\left(\tau_{d}\right)\right)<\left(W^{d}(0)-\Pi^{d}(0)\right)$. By definition of $\tau_{d}, \Pi^{m}\left(\tau_{d}\right)=\Pi^{d}(0)$, hence $W^{m}\left(\tau_{d}\right)<$ $W^{d}(0)$. Thus, whenever the domestic firm prefers competition with $\tau=0$, so does the LSP, i.e., $\tau_{s} \leq \tau_{d}$

\subsection{Minimum standards with externality}

In this section we consider the existence of a consumption externality, for which reason the functional relationship between standard and welfare depends on the externality $L(\tau, q)$. We consider an externality of the type $L(\tau, q)=(b(\tau)-d) q$, with $d>b(\tau)>0, b^{\prime}>0, b^{\prime \prime}<0$. In other words, we assume that consumption produces a negative externality, which rises linearly with consumption per individual. The magnitude of the externality declines when the standard of the product is increased, but at a marginally diminishing rate.

Figure 3 shows social welfare under both monopoly and duopoly for different standards, where $\tau_{c}$ denotes the minimum standard for which the country's welfare is maximized when there are imports, $\tau_{a}$ the minimum standard which maximizes the country's welfare when there are no imports, and $\tau_{b}$ the minimum standard at which the LSP is indifferent between a duopoly and a monopoly.

In order to obtain figure 3 we require, first, that with no standard $(\tau=0)$, there is a strong negative externality, so the higher consumption under duopoly reduces welfare compared to the lower level of consumption under monopoly. Second, as the standard rises, consumption falls at an increasing rate. This condition is likely to hold when the cost of raising standards increases with the standard, as we have assumed. The third condition is that the marginal effect on net welfare of an increase in quality falls as quality increases. Finally, we need that at some level, standards make 


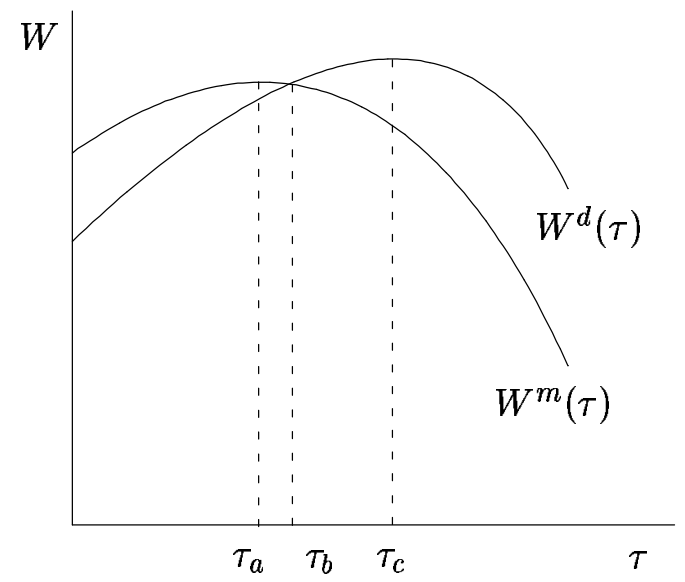

Figure 3: Social welfare as a function of the standard.

production socially unprofitable. In the appendix we show that these conditions are sufficient for welfare functions to appear as in Figure $3 .^{12}$

For each minimum standard $\tau$ only one of the two curves $W^{m}(\tau)$ and $W^{d}(\tau)$ is relevant, depending on the position of $\tau_{\boldsymbol{e}}$ relative to $\tau$. To the right of $\tau_{\boldsymbol{e}}$, the lowest minimum standard that excludes the foreign firm, the relevant curve is $W^{m}(\tau)$, while to the left of $\tau_{\boldsymbol{e}}$ the relevant curve is $W^{d}(\tau)$. Thus, if $\tau_{e}$ lies in the segment $\left[0, \tau_{a}\right]$, a monopoly with minimum standard $\tau_{a}$ is the best option for the LSP. If $\tau_{e} \in\left[\tau_{a}, \tau_{b}\right]$, the LSP maximizes the domestic social welfare by setting the lowest minimum standard that excludes the foreign firm, i.e., $\tau_{\boldsymbol{e}}$. If $\tau_{\boldsymbol{e}} \in\left[\tau_{b}, \tau_{\boldsymbol{c}}\right]$, the LSP chooses the lowest minimum standard compatible with imports, i.e., a standard that is marginally lower than $\tau_{\boldsymbol{e}}$. Finally, if $\tau_{\boldsymbol{e}}>\tau_{\boldsymbol{c}}$ the standard that maximizes the domestic social welfare is $\tau_{\boldsymbol{c}}$. Hence the minimum standard preferred by the LSP is a non-decreasing function of the lowest standard that excludes the foreign firm $\tau_{\boldsymbol{e}}$. If $\tau_{\boldsymbol{e}}$ is greater than $\tau_{b}$, the LSP prefers a duopoly. These results are summarized in Figure 4.

With an externality, the planner tries to balance three effects: the negative effect of the externality, the positive effect of competition on consumers and the negative effect of rent transfers abroad. When the minimum standard that excludes the foreign firm is low, the LSP sets the (positive) standard that maximizes welfare under monopoly, excluding the foreign firm, as we have assumed that with no standard $(\tau=0)$, or a low standard, there is a strong negative externality. For levels of $\tau_{e}$ above $\tau_{a}$, the LSP first chooses $\tau_{e}$ as the standard in order not to export profits. However, profits decrease with the minimum standard, and at a certain level $\left(\tau_{b}\right)$, the relevance of profit-shifting is overshadowed by the positive effect of competition on consumer surplus, and

\footnotetext{
${ }^{12}$ We do not make any claims regarding the ordering or the relative size of the maxima in the two cases.
} 


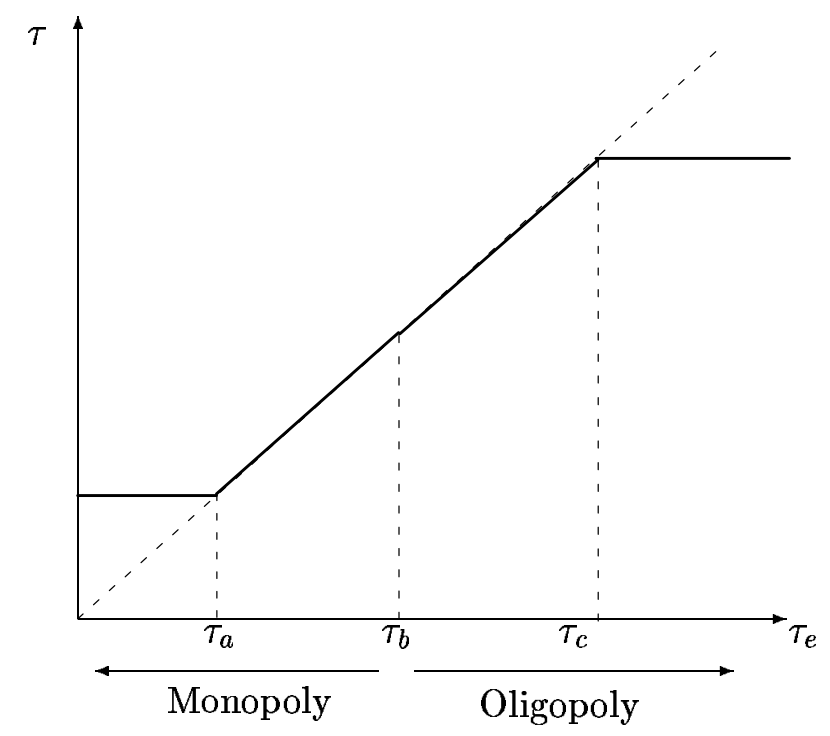

Figure 4: Standard chosen by the LSP as a function of the standard that excludes the foreign firm.

the LSP sets the highest minimum standard that does not exclude the foreign firm. Finally, when $\tau_{e}$ reaches the standard that maximizes social welfare under duopoly, the standard remains at this level. Under duopoly the planner chooses a higher minimum standard than under monopoly. Indeed, under duopoly the volume of production is greater, and with it, the magnitude of the externality, so a more demanding standard is needed. Moreover, under duopoly, part of the costs of a higher minimum standard are absorbed by the foreign producer.

\subsection{Definition of a protectionist standard}

When there is a consumption externality, a standard may be legitimate and lead to an increase in consumer welfare. Even in this case, from the point of view of international trade, a standard may have protectionist motives: in the first place, the planner may be interested in transferring rents from the foreign exporter to the national firm, and secondly, the planner may wish to shift part of the costs of raising standard onto foreign producers as she does not internalize the costs imposed by the new standard on foreign firms. Thus, it is difficult to decide whether minimum standard is being used with protectionist aims when externalities are present. The following definition of a protectionist standard solves this problem:

Definition 1 An minimum standard is said to be non-protectionist when it corresponds to the standard the LSP would use if both firms were domestic. 
In the literature there is a variety of opinion on when a government measure or action is protectionist. According to Baldwin (1970), a measure is protectionist if it lowers real global income. Engel (1997), defines a measure to be protectionist if it reduces global welfare, a definition which includes Baldwin's. We define an alternative criterion for a protectionist measure, under which a measure is protectionist when it differs from what the social planner would impose if all producers were local. Note that our definition coincides with Engel's when there are no externalities.

To appreciate the scope of our definition, let us compare the standards that result from maximizing social welfare when both firms are domestic, with what pertains when there is foreign competition.

Proposition 2 If condition 1 is satisfied, the standard chosen by the LSP is protectionist.

Proof: Consider domestic social welfare under duopoly when one of the firms is foreign:

$$
W^{d}=\int_{0}^{2 q_{h}} p(s) d s-p\left(2 q_{h}\right) q_{h}-c(\tau) q_{h}+2 q_{h}(b(\tau)-d)
$$

If we now consider welfare when both firms are domestic, we have:

$$
W^{D}=\int_{0}^{2 q_{h}} p(s) d s-2 c(\tau) q_{h}+2 q_{h}(b(\tau)-d)
$$

The difference $W^{D}-W^{d}=(p-c) q_{h}$ satisfies:

$$
\frac{d\left(W^{D}-W^{d}\right)}{d \tau}=-c^{\prime}(\tau) q_{h}+\left(p+2 p^{\prime} q_{h}-c\right) \frac{d q_{h}}{d \tau}=p^{\prime} q_{h} \frac{d q_{h}}{d \tau}-c^{\prime}(\tau) q_{h}
$$

where we have used the envelope theorem. This last term is negative given the expression for $d q_{h} / d \tau$ derived in the appendix and condition 1 . This means that the marginal benefit of a rise in minimum standard is greater under duopoly with imports than under a local duopoly, so the minimum standard used in the former case will always be higher.

Q.E.D.

This result reflects the fact that when part of the costs of improving standard can be charged to the foreign firm, the planner demands higher standards than if the two firms are domestic. Note that Proposition 2 also implies that if the foreign country sets the optimal minimum standard (without the threat of imports), it will always choose a lower standard than the home country, confirming that the assumption made earlier on the relative level of standards in the two countries was innocuous. 


\section{Minimum Standards and Relative Market Sizes}

The relative size of the exporting country is an important influence on the effectiveness of standards for protection. As mentioned in the introduction, foreigners might not want to incur in either the fixed cost of producing under two standards or adapting all production to the higher standard of the home country when the home country market is too small. In what follows we formalize this intuition.

We have seen that the minimum standard preferred by both the domestic firm and the LSP depends on the lowest minimum standard that drives away the foreign firm, $\tau_{e}$. In turn the lowest minimum standard that excludes the foreign firm depends on the relative size of the foreign market and on the setup cost for producing under two standards. This section shows that the exclusion standard $\tau_{e}$ is non-increasing function of the relative size of the foreign market. We use $\gamma$ to denote the relative size of the foreign market. We assume that a larger country is equivalent to $\gamma$ copies of the original country. ${ }^{13}$ Since the domestic market remains unchanged, $\gamma$ also represents the relative size of the foreign market in terms of the domestic market. We then assume that the demand function can be written as $q^{*}\left(p^{*} ; \gamma\right)=\gamma q^{*}\left(p^{*}\right)$. Hence, $d p / d \gamma>0$ and $d^{2} p^{*} / d \gamma d q^{*}=$ $-\left(p^{* \prime}+q^{*} p^{* \prime \prime}\right) / \gamma$, which is positive by condition 1 .

Consider first the case when the fixed cost of producing under two standards is sufficiently high that this option is irrelevant. Then we show in Lemma 1 that the lowest standard that excludes imports is a decreasing function of $\gamma$. The intuition of this result is simple: as the size of the foreign market increases, so does the cost to the foreign firm of producing at the standard level required in the export market.

Lemma 1 Assume condition 1 is satisfied. Then, as the relative size of the foreign market increases, the standard required to drive away the foreign firm falls, $d \tau_{e} / d \gamma<0$.

Proof: Totally differentiating both terms of the exclusion condition (8) with respect to $\gamma,{ }^{14}$ and using the Envelope Theorem, we obtain

$$
\left.q^{*}(0) \frac{d p^{*}}{d \gamma}\right|_{p^{*}\left(q^{*}(0)\right)}-\left.q^{*}\left(\tau_{e}\right) \frac{d p^{*}}{d \gamma}\right|_{p^{*}\left(q^{*}\left(\tau_{e}\right)\right)}=\left(p^{\prime} q_{f}\left(\tau_{e}\right) \frac{d q_{h}}{d \tau}-c^{\prime}\left(\tau_{e}\right)\left(q_{f}\left(\tau_{e}\right)+q^{*}\left(\tau_{e}\right)\right)\right) \frac{d \tau_{e}}{d \gamma}
$$

but since $q^{*}(0)>q^{*}\left(\tau_{e}\right)$ and $d^{2} p^{*} / d \gamma d q^{*}>0$, the RHS of (10) is positive, which implies that the proposition is valid if the term in brackets in (10) is negative. Recalling equation (13) in the appendix, the bracketed term in (10) is negative if

\footnotetext{
${ }^{13}$ This will become important since, given the fact that the effect of the externality depends on consumption per individual, standards should be the same everywhere, absent other reasons such as protection.

${ }^{14}$ Due to the high fixed costs of setting up production under two standards, (8) becomes $\Pi_{0}^{*}(\tau)=\Pi_{1}^{*}(\tau)$
} 


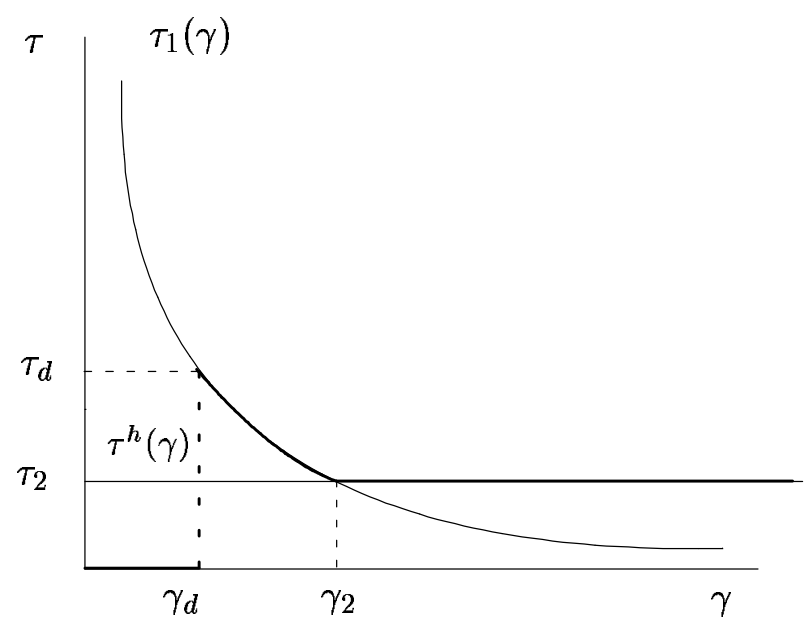

Figure 5: Minimum standard desired by the domestic firm

$$
\frac{p^{\prime} q_{f}}{2 p^{\prime \prime} q_{h}+3 p^{\prime}}-\left(q_{f}+q^{*}\right)<0
$$

which is true, since $p^{\prime \prime} q_{h}+p^{\prime}<0$, by condition 1 . Note that the proposition implies there is a one-to-one relation between the two variables $\gamma$ and $\tau$.

Q.E.D.

Now, consider the case in which the fixed $\operatorname{cost} F$ is such that producing under two standards is economically viable. Define the function $\tau_{1}(\gamma)$ as the standard that excludes exports when the foreign firm operates under a single standard, for each size of the foreign country (i.e., the $\tau_{e}$ in the previous lemma). Let $\tau_{2}$ be the standard such that $p\left(q_{h}\left(\tau_{2}\right)+q_{f}\left(\tau_{2}\right)\right) q_{f}\left(\tau_{2}\right)-c\left(\tau_{2}\right) q_{f}\left(\tau_{2}\right)-F=0$ and define $\gamma_{2}$ as the relative country size at which $\tau_{1}(\gamma)=\tau_{2}$. Then $\gamma_{2}$ is the foreign country size at which the two exclusion conditions in (8) coincide. Note that $\tau_{2}$ is an decreasing function of $\mathrm{F}$, because higher fixed costs makes adopting the foreign standard for exports less attractive, but $\tau_{2}$ is independent of $\gamma$. If $\tau>\tau_{2}$, the foreign firm never operates under two standards. Then $\tau_{e}(\gamma)=\max \left\{\tau_{1}(\gamma), \tau_{2}\right\}$ is the lowest minimum standard that precludes exports for each size of the foreign country. This function is depicted in bold in Figure 5.

In what follows we will use Figure 5 to show that if the foreign market is sufficiently small, the local producer prefers a duopoly with zero standard to a nonzero standard. Recall that $\tau_{d}$ is the lowest minimum standard (set by government) such that the domestic firm prefers a duopoly. Assume first that $\tau_{d}>\tau_{2}$, as depicted in Figure 5. In this case define $\gamma_{d}$ as the value of $\gamma$ for which 
$\tau_{e}(\gamma)=\tau_{d}$. Thus, $\gamma_{d}$ is the smallest relative foreign market size for which it suits the domestic firm to exclude the foreign firm by means of a minimum standard. In effect, if $\gamma<\gamma_{d}$, then the standard that precludes exports $\left(\tau_{e}(\gamma)\right)$ is higher than the lowest minimum standard at which the domestic firm prefers a duopoly $\left(\tau_{d}\right)$. On the contrary, if $\gamma>\gamma_{d}$, the standard that precludes exports is attractive for the domestic firm, i.e., $\tau_{e}(\gamma)<\tau_{d}$.

Thus the curve in bold $\tau^{h}(\gamma)$ in Figure 5 indicates the minimum standard desired by the local firm for each foreign market size. The minimum standard is 0 for relative sizes less than $\gamma_{d}$. When this size is attained, the desired standard jumps to $\tau_{d}$. Once $\gamma_{d}$ is exceeded, any further increase in the size of the foreign market reduces the standard desired by the domestic firm according to the function $\tau_{1}(\gamma)$. However, when the size of the foreign country exceeds $\gamma_{2}$, the standard that excludes the foreign firm remains constant at $\tau_{2}$, because in this region it is more profitable for the foreign firm to produce under two standards than under one standard if it wants to export.

Finally, in the case when $\tau_{d}<\tau_{2}$, the domestic firm will never want to exclude the foreign firm, for any relative size of the foreign market. To see this, note that when $\tau>\tau_{d}$, the home firm prefers a duopoly with $\tau=0$ to a monopoly with standard $\tau$ (Figure 2). On the other hand, when $\tau<\tau_{d}$, the foreign firm exports independently of the size of the foreign market (see Figure 5).

\section{Social Welfare and Relative Size of the Foreign Market}

This section studies the relationship between the size of the foreign market and the minimum standard that maximizes social welfare in the home market. We first analyze the case where there is no consumption externality.

The only difference between this case and the choice of the domestic firm is that the LSP includes consumer welfare in its objective function. Hence, the LSP is less willing to exclude the foreign firm. As we have shown before, the maximum minimum standard $\tau_{s}$ such that the LSP prefers a monopoly is lower than $\tau_{d}$. Hence, there is a larger range of countries for which the LSP prefers a duopoly with no standard, unless $\tau_{2}<\tau_{d}$, in which case, both the LSP and the domestic firm prefer a duopoly with no standard for all sizes of the foreign country (see Figure 5).

Next we consider the existence of a consumption externality. Figure 4 shows the relationship between the standard chosen by the LSP and the lowest minimum standard that excludes the foreign firm. In turn, Figure 5 shows in bold the minimum standard that excludes the foreign firm as a function of the relative size of the foreign market.

¿From these figures we construct the function that relates the minimum standard chosen by the LSP to the relative size of the foreign market. The precise form of this curve depends on the setup cost $F$. We consider first the case when $F$ is relatively high implying that $\tau_{2}<\tau_{a}$ and the option of producing under two standards is irrelevant. Let $\gamma_{a}, \gamma_{b}$, and $\gamma_{c}$ be the values that satisfy $\tau_{a}=\tau\left(\gamma_{a}\right), \tau_{b}=\tau\left(\gamma_{b}\right)$, and $\tau_{c}=\tau\left(\gamma_{c}\right)$, respectively. ${ }^{15}$ Then Figure 6 shows the functional relation 


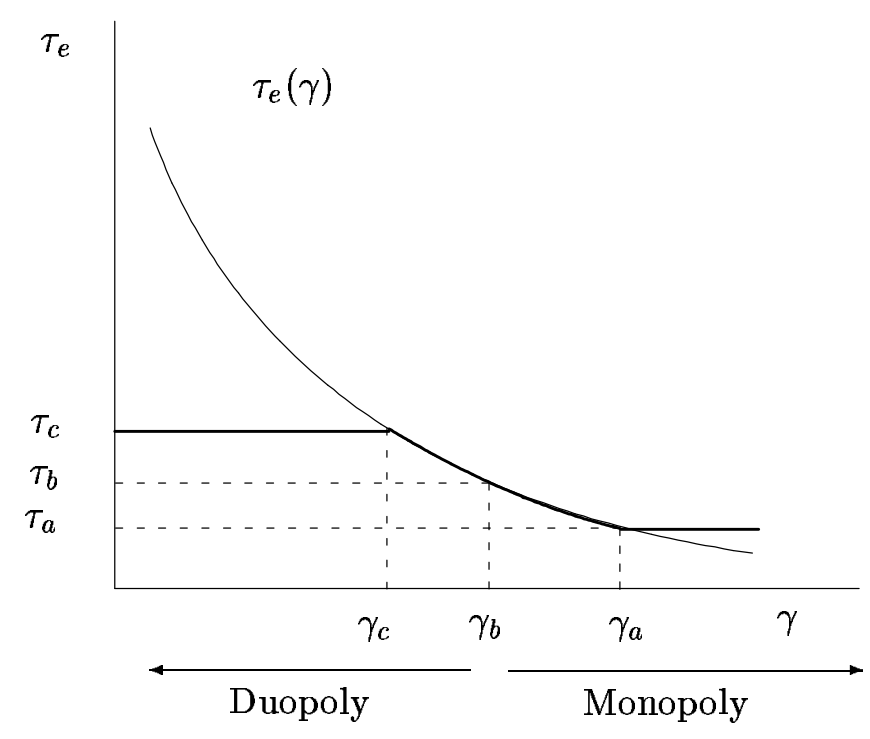

Figure 6: Minimum standard desired by the planner, case with externality.

between foreign market size and the minimum standards chosen by the LSP.

1. When the foreign country is greater than $\gamma_{2}$, the lowest minimum standard that excludes the foreign firm is $\tau_{e}=\tau_{2}$. Since $\tau_{2}<\tau_{a}$ by assumption, $\tau_{e}<\tau_{a}$, and the LSP chooses $\tau_{a}$ (see Figure 4), precluding imports.

2. If $\gamma \in\left[\gamma_{2}, \gamma_{a}\right]$, the lowest minimum standard that excludes the foreign firm is still less than $\tau_{a}$. Hence the chosen standard is again $\tau_{a}$.

3. If $\gamma \in\left[\gamma_{a}, \gamma_{b}\right]$, the minimum standard that excludes the foreign firm lies in the segment $\left[\tau_{a}, \tau_{b}\right]$. In this region, exclusion is preferable, so the LSP maximizes the domestic social welfare by setting the lowest minimum standard that excludes the foreign firm, i.e., $\tau_{\boldsymbol{e}}$.

4. If $\gamma \in\left[\gamma_{b}, \gamma_{c}\right], \tau_{e} \in\left[\tau_{b}, \tau_{c}\right]$, a duopoly is preferable and the LSP chooses the lowest minimum standard compatible with imports, i.e., a standard marginally lower than $\tau_{e}$.

5. Finally, if $\gamma<\gamma_{c}, \tau_{e}>\tau_{c}$, and the standard that maximizes the domestic social welfare is $\tau_{c}$, i.e., the one that maximizes welfare under duopoly.

If, starting from a low level, the size of the foreign market increases, eventually a point is reached where the initial standard will not allow the duopoly to be sustained. The planner lowers

\footnotetext{
${ }^{15}$ See Figure 3 for the meaning of the standards.
} 
the standard and chooses the highest standard compatible with duopoly, i.e. $\tau_{e}(\gamma)$ (bold curve in Figure 6). As the size of the foreign market is increased, the minimum standard needs to be continuously lowered, which raises the firms' rents. Eventually a point $\left(\gamma_{b}\right)$ is reached where the planner prefers to exclude the foreign producer, as the benefits from profits transferred to the local producer are greater than the losses caused by eliminating foreign competition. In this segment, the LSP chooses the lowest standard that eliminates the foreign producer. Hence, the minimum standard selected by the LSP is a non-increasing function of the relative size of the foreign market

We now compare the standards desired by the domestic firm with those that maximize social welfare. ${ }^{16}$ It can be seen that when $\gamma \in\left[0, \gamma_{d}\right]$, the standard desired by the LSP is positive and therefore greater than the null standard that the firm would choose. There are two cases that must be analyzed. First, if $\gamma_{d}<\gamma_{c}$, the firm desires higher than socially-optimum standards in the range $\left[\gamma_{d}, \gamma_{c}\right]$. In the segment $\left[\gamma_{c}, \gamma_{b}\right]$, the standard levels preferred by the LSP and the firm are nearly identical, except for the fact that the standard desired by the firm is marginally higher, so as to exclude imports. When the foreign market is bigger than $\gamma_{a}$, the social planner sets a constant standard level above the one desired by the domestic firm. Second, if $\gamma_{d}>\gamma_{c}$, the standard desired by the firm is always below the level chosen by the LSP.

We have analyzed the case when $\tau_{2}<\tau_{a}$. At the other extreme, when the setup $\operatorname{cost} F$ is relatively low, we have $\tau_{2}>\tau_{c}$. In this case, when $\gamma>\gamma_{2}$, the lowest minimum standard that excludes the foreign firm is $\tau_{2}$, and since $\tau_{2}>\tau_{c}$, the LSP chooses $\tau_{c}$, allowing imports. When $\gamma<\gamma_{2}$, the lowest minimum standard that excludes the foreign firm is greater than $\tau_{2}$, and since $\tau_{2}>\tau_{c}$, the LSP again chooses $\tau_{c}$. Hence, when the cost to the foreign firm of producing under two standards is low, the LSP considers that the cost of excluding exports is too high and sets the optimum standard for duopoly. The remaining cases, i.e. intermediate setup costs, lie between the two extreme cases analyzed.

\section{Conclusions}

The purpose of this paper has been to examine the protectionist effects of non-discriminatory standards. One of the paper's results is that it provides a consistent definition of a protectionist standard. According to our definition, a minimum standard is protectionist when it exceeds what a planner would impose if all producers were local. There are two possible reasons for this behavior: firstly, the planner wishes to transfer rents to local producers, and secondly, the planner knows that part of the costs of reducing the negative externality will be absorbed by foreign firms. Using this definition of a protectionist standard, we show that the minimum standard chosen by the social planner is always protectionist.

$¿$ From the point of view of the import-substituting firm, a minimum standard that excludes the

\footnotetext{
${ }^{16}$ That is, we compare Figure 5 with Figure 6 . Recall that $\tau_{2}$ is so low that only $\tau_{1}(\gamma)$ is relevant.
} 
foreign firm has the favorable effect of eliminating competition in the local market, but tends to raise its own production costs, thereby reducing the concomitant monopoly profits. Therefore, the minimum standard desired by the domestic firm is not always higher than that chosen by the social planner. In particular, consider the case where the setup cost for producing a second standard is relatively high. Then there is a relationship between the relative size of the foreign market and the minimum standard that excludes the foreign firm from the domestic market. When the foreign market is relatively small and the foreign firm has few alternatives for its production, it requires a high minimum standard to exclude it from the domestic market. The standard that excludes the foreign firm turns out to be expensive for the local firm, which therefore prefers no minimum standard. On the other hand, the planner, who incorporates the negative effect of the externality, will impose a standard. When the foreign market is big, it is easy to exclude the foreign firm, which has to raise standards over its entire production. The domestic firm desires the lowest minimum standard that keeps imports out, which in general is lower than the one set by the planner. However, there might exist an intermediate size range (of the foreign country) for which the domestic firm prefers a higher standard than the planner.

What policy conclusions can be drawn from this paper? In the first place, our results allow us to deduce which industries there will face significant pressure by local producers for protectionist minimum standards. These will be industries where foreign competition has significant alternative markets available and the cost of setting up production for a second standard is high. Second, standards will be more effective in protecting relatively small countries. Third, when the fixed setup cost of setting production under two standards is high, large exporting countries are more likely to press for regulatory changes rather than adapt to unreasonable standards. On the other hand, small countries are more likely to adopt the standards of the export market.

This paper has focused on the case of quantity competition, so it is natural to wonder whether the results would be different under price competition. It is easy to verify that most of the conclusions remain unchanged. Under price competition with homogenous goods the domestic market settles at the Bertrand equilibrium in the domestic market, which means that the profits of both firms (in that market) are zero. Given that the foreign firm does not obtain a return from exporting to the domestic market, it will reject any standard which raises cost in its own market or alternatively, that requires it to incur the fixed cost of setting up production under two standards. Hence, the domestic firm prefers the minimum standard which keeps the foreign competitor out, i.e. just above the null standard. From the planner's point of view, if there is no externality, the optimum standard is zero, because there is no rent transfer abroad. When there is an externality, the LSP faces the problem of not being able to raise standards without eliminating the foreign competitor. The LSP has only two options: no standard under duopoly, or the optimum standard under monopoly. As can be seen, the analysis is much simpler in the case of price competition.

Our results depend on several specific conditions in the model, but we believe that they reflect 
real problems in applying minimum standard restrictions. Two assumptions in the paper should be relaxed in future research. First, the assumption that the domestic firm solely sells in the local market and, second, that the externality depends on consumption relative to the size of the country and not on the absolute level of consumption, which is the relevant case when a larger country reflects increased density. We leave for future research the analysis of the more general case when both firms export. In particular, we are interested in modelling the standard-setting game between the two governments. In this paper we have considered standards as the only instrument of the LSP. An alternative would be to consider the use of taxes based directly on the externality. 


\section{A Appendix}

\section{A.1 Proof of Proposition 1}

\section{Proposition 1 If condition 1 is fulfilled}

1. The foreign firm's profits from exports fall as the minimum standard is raised in $H$.

2. Under monopoly, the domestic firm's profits fall as the minimum standard is raised.

Proof: Differentiating the foreign firm's first-order conditions for sales in its own market with respect to $\tau$, gives:

$$
\frac{d\left(d \Pi^{*} / d q^{*}\right)}{d \tau}=\frac{d\left(p^{* \prime} q^{*}+p^{*}-c(\tau)\right)}{d \tau}=\left(p^{* \prime \prime} q^{*}+2 p^{* \prime}\right) \frac{d q^{*}}{d \tau}-c^{\prime}(\tau)=0
$$

which implies (using condition 1)

$$
\frac{d q^{*}}{d \tau}=\frac{c^{\prime}(\tau)}{\left(p^{* \prime \prime} q^{*}+2 p^{* \prime}\right)}<0
$$

Totally differentiating the two firms' first-order conditions in the local market $\left(d \Pi / d q_{i}=p^{\prime} q_{i}+p-\right.$ $c=0, i=1,2$ ) with respect to standard $\tau$, gives:

$$
\left[\begin{array}{cc}
p^{\prime \prime} q_{h}+2 p^{\prime} & p^{\prime \prime} q_{h}+p^{\prime} \\
p^{\prime \prime} q_{f}+p^{\prime} & p^{\prime \prime} q_{f}+2 p^{\prime}
\end{array}\right]\left[\begin{array}{c}
\frac{d q_{h}}{d \tau} \\
\frac{d q_{f}}{d \tau}
\end{array}\right]=\left[\begin{array}{c}
c^{\prime}(\tau) \\
c^{\prime}(\tau)
\end{array}\right]
$$

Given the symmetry of the model in the local market, we have $q_{h}=q_{f}$ in equilibrium, which means that the determinant of the matrix in (12) is $\Delta=p^{\prime}\left(2 p^{\prime \prime} q_{h}+3 p^{\prime}\right)<0$. Applying Cramer's Rule and condition 1 we have:

$$
\frac{d q_{i}}{d \tau}=\frac{c^{\prime}(\tau)}{\left(2 p^{\prime \prime} q_{i}+3 p^{\prime}\right)}<0
$$

Thus the effect of an increase in minimum standards on the profits of the foreign firm (4) is:

$$
\frac{d \Pi^{*}}{d \tau}=\left(p^{* \prime} q^{*}+p^{*}-c\right) \frac{d q^{*}}{d \tau}-c^{\prime}(\tau) q^{*}+\left(p^{\prime} q_{f}+p-c\right) \frac{d q_{f}}{d \tau}+p^{\prime} q_{f} \frac{d q_{h}}{d \tau}-c^{\prime}(\tau) q_{f}
$$

Given that the first-order conditions for profit maximization continue to be fulfilled (an application of the Envelope Theorem), this expression reduces to:

$$
\frac{d \Pi^{*}}{d \tau}=-c^{\prime}(\tau)\left(q^{*}+q_{f}\right)+p^{\prime} q_{f} \frac{d q_{h}}{d \tau}
$$


The above expression can be rewritten using (13):

$$
\frac{d \Pi^{*}}{d \tau}=c^{\prime}(\tau) q_{f}\left(\frac{p^{\prime}}{2 p^{\prime \prime} q_{h}+3 p^{\prime}}-\left(1+\frac{q^{*}}{q_{f}}\right)\right)
$$

The first term in the brackets is less than 1 , since the denominator can be written as $p^{\prime}+2\left(p^{\prime \prime} q_{h}+\right.$ $p^{\prime}$ ), which, by condition 1 , is larger in absolute value than $p^{\prime}$. This means that the derivative $d \Pi^{*} / d \tau$ is negative. A similar argument shows that the profits of the domestic firm under monopoly also fall as $\tau$ is raised:

$$
\frac{d \Pi^{m}}{d \tau}=-c^{\prime}(\tau) q_{h}<0
$$

Q.E.D.

\section{A.2 Conditions on Welfare}

This part of the appendix finds conditions that ensure the welfare functions shown in Figure 3.

Condition 2: $W^{d}(0)<W^{m}(0), \quad d^{2} q_{i} / d \tau^{2}<0, \quad d^{2}\left[(b-d-c) q_{h}\right] / d \tau^{2}<0, \quad c^{\prime}(0)=0$, and $\lim _{\tau \rightarrow \infty} c(\tau)>p(0)$.

Lemma: If condition 2 holds, then:

1. The welfare functions $W^{d}, W^{m}$ are concave.

2. The welfare functions $W^{d}, W^{m}$ have interior maxima $\tau_{c}$ and $\tau_{a}$ respectively.

3. These maxima satisfy $\tau_{c}>\tau_{a}$.

Proof: From the social welfare expressions (7) and (6),we obtain:

$$
\frac{d W^{m}}{d \tau}=\left[p^{m}-c(\tau)+b(\tau)-d\right] \frac{d q_{h}^{m}}{d \tau}+\left[b^{\prime}(\tau)-c^{\prime}(\tau)\right] q_{h}^{m}
$$

and

$$
\frac{d W^{d}}{d \tau}=\left[p^{d}-c(\tau)+b(\tau)-d\right] \frac{d q_{h}^{d}}{d \tau}+2\left[b^{\prime}(\tau)-c^{\prime}(\tau)\right] q_{h}^{d}+\left[c^{\prime}(\tau)-2 p^{\prime} \frac{d q_{h}^{d}}{d \tau}\right] q_{h}^{d}+[b(\tau)-d] \frac{d q_{h}^{d}}{d \tau}
$$

where $q_{h}^{m}$ and $q_{h}^{d}$ denote the quantities produced by the domestic firm under monopoly and duopoly respectively. The condition $c^{\prime}(0)=0$ implies that $d q_{h} / d \tau=0$ at $\tau=0$ (see equation (13)). This condition, combined with the fact that $b^{\prime}>c^{\prime}$ at $\tau=0$ shows that $W^{m}$ and $W^{d}$ are increasing at 
$\tau=0$. This allows us to state that the social-welfare-optimizing minimum standards are always strictly positive. Concavity of $W^{m}$ follows from the fact that we can write

$$
\frac{d^{2} W^{m}}{d \tau^{2}}=\frac{d\left(p^{m}\left[d q_{h}^{m} / d \tau\right]\right)}{d \tau}+\frac{d^{2}\left[(b-d-c) q_{h}^{m}\right]}{d \tau^{2}}<0
$$

and that the first term can be written as $p^{m \prime}\left(d q_{h}^{m} / d \tau\right)^{2}+p^{m} d^{2} q_{h}^{m} / d \tau^{2}$. This expression is negative because the first term is negative by (13) while the second is negative by condition 2 . An analogous derivation shows that $W^{d}$ is also concave. ${ }^{17}$ Finally, to show that local optima $\tau_{c}$ and $\tau_{a}$ exist, we use the fact that when standards are high, costs are higher than prices so production ceases and welfare is zero.

The last two terms of the equation (16) are positive. Additionally, we have that $2 q_{h}^{d} \geq q_{h}^{m} \geq q_{h}^{d}$, which, in turn, implies that $p^{d} \leq p^{m}$. Given Condition 1, expressions (11) and (13) imply

$$
\frac{d q_{h}^{m}}{d \tau} \leq \frac{d q_{h}^{d}}{d \tau} \leq 0
$$

which gives:

$$
\frac{d W^{d}}{d \tau} \geq \frac{d W^{m}}{d \tau}
$$

and this implies that $\tau_{c}>\tau_{a}$.

Q.E.D.

\footnotetext{
${ }^{17}$ In the case of duopoly, the third condition becomes $d^{2}\left[(2 b-2 d-c-p) q^{d}\right] / d \tau^{2}<0$.
} 


\section{References}

Baldwin, Robert E. (1970): "Nontariff Distortions of International Trade," The Brookings Institution, Washington.

Barrett, S. (1994): "Strategic Environmental Policy and International Trade," Journal of Public Economics, 54, 325-338.

Bockstael, Nancy E., 1984, "The Welfare Implications of Minimum Quality Standards," American Journal of Agricultural Economics, 66, 466-71.

Boom, A. (1995): "Asymmetric International Minimum Quality Standards and Vertical Differentiation," The Journal of Industrial Economics, XLIII(1), 101-120.

Brander, J. and B. Spencer (1985): "Export Subsidies and Market share Rivalry," J. of International Economics, 18, 83-100.

Bredahl, M., A. Schmitz and J. Hillman (1987): "Rent Seeking in International Trade: The Great Tomato War," Journal of Agricultural Economics, February, 1-10.

Chambers, Robert G., and Michael Weiss (1992): "Revisiting Minimum Quality Standards," Economic Letters,40, 197-201.

Copeland, B. and M. Scott Taylor (1995): "Trade and the Environment: A Partial Synthesis", American Journal of Agricultural Economics, 77, 765-71.

Das, S. and S. Donnenfeld (1987): "Trade Policy and its Impact on the Quality of Imports," Journal of International Economics, 23, 77-95.

Das, S. and S. Donnenfeld (1989): "Oligopolistic Competition and International Trade: Quantity and Quality Restrictions," Journal of International Economics, 27, 299-318.

Engel, E. (1996): "Uvas Envenenadas, Vacas Locas y Proteccionismo," , en Fischer, R. (editor), Las Nuevas Caras del Proteccionismo, Dolmen, Santiago.

Fischer, R and P. Serra (1997): "Protecci

'on y Est

'andares", en Fischer, R. (editor), Las Nuevas Caras del Proteccionismo, Dolmen, Santiago.

Kennedy (1994): "Equilibrium Pollution Taxes in Open Economies with Imperfect Competition," J. of Environmental Economics and Management, 27, 49-63.

National Research Council, (1995): "Standards, Conformity Assessment and Trade," National Academy Press, Washington, DC. 